\title{
Mechanism and Kinetics Study for Photocatalytic Oxidation Degradation: A Case Study for Phenoxyacetic Acid Organic Pollutant
}

\author{
Kian Mun Lee, Sharifah Bee Abd Hamid, and Chin Wei Lai \\ Nanotechnology \& Catalysis Research Centre (NANOCAT), 3rd Floor, Block A, Institute of Postgraduate Studies (IPS), \\ University of Malaya, 50603 Kuala Lumpur, Malaysia
}

Correspondence should be addressed to Sharifah Bee Abd Hamid; sharifahbee@um.edu.my

Received 13 April 2015; Revised 23 May 2015; Accepted 25 May 2015

Academic Editor: Thomas Stergiopoulos

Copyright (C) 2015 Kian Mun Lee et al. This is an open access article distributed under the Creative Commons Attribution License, which permits unrestricted use, distribution, and reproduction in any medium, provided the original work is properly cited.

\begin{abstract}
Photocatalysis is a rapidly expanding technology for wastewater treatment, including a wide range of organic pollutants. Thus, understanding the kinetics and mechanism of the photocatalytic oxidation (PCO) for degradation of phenoxyacetic acid (PAA) is an indispensable component of risk assessment. In this study, we demonstrated that the central composite design (CCD) coupled with response surface methodology (RSM) was successfully employed to probe the kinetics and mechanism of PCO degradation for PAA using an efficient zinc oxide ( $\mathrm{ZnO}$ ) photocatalyst. In our current case study, four independent factors such as $\mathrm{ZnO}$ dosage, initial concentration of PAA, solution $\mathrm{pH}$, and reaction time on the PCO degradation for PAA were examined in detail. Based on our results obtained from RSM analyses, an efficient pathway leading to the high degradation rate (>90\%) was applying $0.4 \mathrm{~g} / \mathrm{L}$ of $\mathrm{ZnO}$ dosage with $16 \mathrm{mg} / \mathrm{L}$ of concentration of PAA at $\mathrm{pH} 6.73$ for 40 minutes. The experimental results were fitted well with the derived response model with $R^{2}=0.9922$. This study offers a cost-effective way for probing our global environmental water pollution issue.
\end{abstract}

\section{Introduction}

Lately, global warming poses one of the most serious threats to the global environment ever faced in human history, especially water pollution. One of the major water pollutants is the use of pesticides and herbicides in agricultural fields that created severe environmental issue, which are considered a wide variety of persistent organic pollutants introduced into the natural water resources or wastewater treatment systems. In fact, the release of the persistent organic structure with toxicity property may cause negative effects on the environment and human health as the persistent organic structure compounds are very toxic and chemically stable and resist biodegradation [1-4]. The control of persistent organic pollutants in our natural water resources or wastewater treatment systems is an important issue. It is a wellknown fact that PAA is a parent molecule for herbicides and pesticides for weed control. In particular, the discharge of this PAA effluent into the natural water resources or wastewater treatment systems is undesirable. This is due to PAA possess various bioactivities, including anticancer, antitumor, analgesic, anti-inflammatory, inhibition of plant growth process and antimicrobial, which are harmful to human health [5-7]. Thus, PAA was selected as the model pollutant in our kinetics and mechanism study of direct oxidation organics in order to create a green and healthy living environment for our next generation.

In recent years, advanced oxidation processes (AOPs) system has attracted great interest from science community as the most promising way to solve the environmental problems, especially getting rid of residual dyes pollutants and mineralization and detoxification of various organic pollutants from wastewater stream [8-11]. In this manner, AOPs system is considered to be an ideal green environmental solution to realize our green economy future. In the field of photocatalysis today, $\mathrm{ZnO}$-mediated heterogeneous photocatalyses have received increased interest due to their capability in degrading numerous kinds of contaminants 


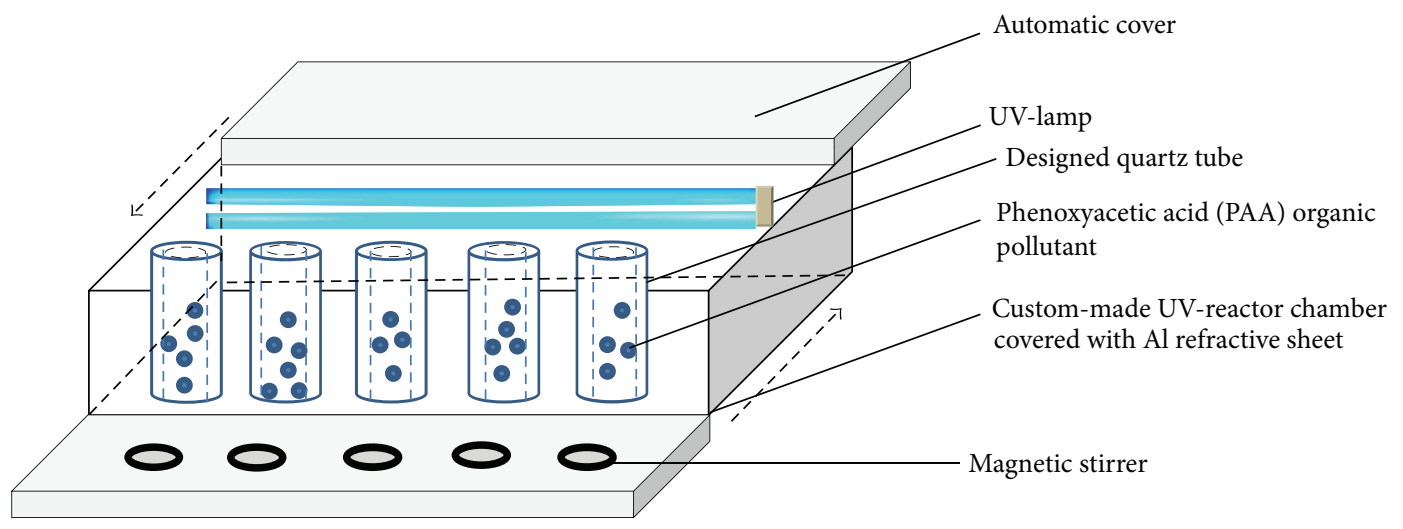

FIGURE 1: Experimental setup for the photocatalytic degradation of PAA.

into carbon dioxide and water [12-14]. Furthermore, $\mathrm{ZnO}$ catalysts emerged as the leading candidate in photocatalysis and appeared as a potential photocatalyst due to low cost, easy availability, excellent chemical stability, nontoxicity in nature, and high initial rate of activities $[15,16]$. Moreover, $\mathrm{ZnO}$ is relatively cheaper and is able to absorb a wide range of UV spectrum compared to that of titanium dioxide $\left(\mathrm{TiO}_{2}\right)$ [17].

Several researchers have reported the removal of PAA from aqueous media by utilizing the titanium dioxide as the photocatalyst through conventional study $[4,18,19]$. However, an obvious hindrance to the widespread use of $\mathrm{TiO}_{2}$ as a photocatalyst in this way is that it is time consuming and not cost-effective as more experiments need to be carried out in PAA removal if changing one parameter while fixing other processing parameters at constant value. Making intuitive guesses on their optimum processing parameters is more or less impossible, and a focused research on the area is a very challenging task. In this case study, response surface methodology (RSM) was applied in optimizing photocatalytic oxidation of various organics. This method is more practical by taking into account the interactive effects among the process parameters and could determine the optimal experimental conditions accurately with minimum labours $[20,21]$.

To the best of our knowledge, PAA removal using $\mathrm{ZnO}$ photocatalyst is still lacking at current stage. The optimization of PAA via multivariate approach has been developed in our case study. In this work, central composite design coupled with response surface study was adopted to optimize four process parameters, namely, $\mathrm{ZnO}$ loading, initial concentration of PAA, solution $\mathrm{pH}$, and reaction time on the photocatalytic degradation of PAA. The kinetics and mineralization of PAA will be investigated and its possible photocatalytic degradation mechanism was proposed.

\section{Experimental}

2.1. Materials. Phenoxyacetic acid $\left(\mathrm{C}_{8} \mathrm{H}_{8} \mathrm{O}_{3}, 99 \%\right.$ purity) was obtained from Sigma Aldrich. Zinc oxide (ZnO, 99\% purity) was obtained from Merck. $\mathrm{NaOH}$ and $\mathrm{HNO}_{3}$ obtained from Merck were used to adjust the $\mathrm{pH}$ of the reaction medium. All reagents were of analytical grade and were used without further purification. Deionized water was used for the preparation of all aqueous solutions.

2.2. Photocatalytic Degradation of Phenoxyacetic Acid. $100 \mathrm{mg} / \mathrm{L}$ PAA solution was prepared by dissolving $0.05 \mathrm{~g}$ of powder in $500 \mathrm{~mL}$ of deionized water. The solutions used in the photodegradation process were prepared by diluting the stock solution to the desired concentration. Typically, a certain amount of the $\mathrm{ZnO}$ photocatalyst was loaded into $100 \mathrm{~mL}$ of PAA with known concentration in a quartz vessel. The experiments were carried out in a batch reactor as shown in Figure 1. This suspended solution was allowed to equilibrate for 15 minutes in the dark at room temperature $\left(28 \pm 2^{\circ} \mathrm{C}\right)$. Then a $96 \mathrm{~W}$ UV lamp $(\lambda=$ $365 \mathrm{~nm}$ ) was switched on to initiate the photocatalytic degradation process. The reaction medium was agitated and was bubbled with air throughout the experiment to maintain homogeneous environment. The aliquot was then filtered by a $0.22 \mu \mathrm{m}$ Nylon filter to remove the catalyst particles. Prior to analysis, a calibration curve was constructed using a series of standard solutions with known concentrations $\left(R^{2}=0.9990\right)$. The concentration of PAA from the PCO experiments was determined by a Perkin Elmer Lambda $35 \mathrm{UV}$-Vis spectrophotometer at the $\lambda_{\max }$ of $269 \mathrm{~nm}$. The percentage of degradation was determined using

$$
\% \text { Degradation }=\frac{C_{0}-C_{t}}{C_{0}} \times 100,
$$

where $C_{0}$ is the initial concentration of PAA in $\mathrm{mg} / \mathrm{L}$ and $C_{t}$ is the concentration of PAA in $\mathrm{mg} / \mathrm{L}$ at the end of experiment. The degree of mineralization was determined from Total Organic Carbon (TOC) analysis (in-house, based on HACH method).

2.3. Response Surface Methodology. A central composite design (CCD) with four factors and five coded levels was adopted in the optimization study. Table 1 depicts the experimental ranges and levels of the process parameters. In the present study, the amount of $\mathrm{ZnO}$ loaded $(A)$, initial concentration of PAA $(B)$, solution $\mathrm{pH}(C)$, and reaction time $(D)$ were selected as the independent variables. 
TABLE 1: Independent variables and experimental range for degradation of PAA.

\begin{tabular}{|c|c|c|c|c|c|c|c|}
\hline \multirow{2}{*}{ Parameters } & \multirow{2}{*}{ Unit } & \multirow{2}{*}{ Symbol } & \multicolumn{5}{|c|}{ Range } \\
\hline & & & -2 & -1 & 0 & +1 & +2 \\
\hline $\mathrm{ZnO}$ loading & $\mathrm{g} / \mathrm{L}$ & $A$ & 0.20 & 0.30 & 0.40 & 0.50 & 0.60 \\
\hline Initial concentration of PAA & $\mathrm{mg} / \mathrm{L}$ & $B$ & 10.00 & 15.00 & 20.00 & 25.00 & 30.00 \\
\hline Solution $\mathrm{pH}$ & & C & 5.00 & 6.00 & 7.00 & 8.00 & 9.00 \\
\hline Reaction time & $\min$ & $D$ & 10.00 & 20.00 & 30.00 & 40.00 & 50.00 \\
\hline
\end{tabular}

The percentage degradation of PAA $(R)$ was selected as the output dependent variable. Other factors such as stirring rate, temperature, light intensity, and oxygen supply were held constant. The response variable was fitted by a highly structured and flexible second-order model:

$$
R=\beta_{o}+\sum_{j=1}^{k} \beta_{j} x_{j}+\sum_{j=1}^{k} \beta_{j j} x_{j}^{2}+\sum_{i<j} \sum_{=2}^{k} \beta_{i j} x_{i} x_{j},
$$

where $R$ is the predicted degradation percentage of PAA (\%), $\beta_{o}$ is the constant term, $\beta_{j}$ is the linear coefficients, $\beta_{j j}$ is the quadratic coefficients, $\beta_{i j}$ is the coefficient of the interaction parameters, and $x_{i}$ and $x_{j}$ represent the coded values of the independent variables [22-24]. The optimization study was performed using Design Expert software version 8.0.6 from Stat Ease Inc., USA.

\section{Results and Discussion}

3.1. Multivariate Regression Analysis. A total of 30 sets of batch experiments were carried out via CCD based on response surface methodology to investigate the interaction between the main and studied operational factors. Table 2 shows the experimental and predicted values of photocatalytic degradation of PAA under designed conditions. The adequacy of the model was further evaluated through analysis of variance (ANOVA) statistics ( $F$-test, $t$-test, adjusted $R^{2}$, and lack-of-fit) and the results are depicted in Table 3 [22]. The ANOVA of the derived response model indicates that the model is highly significant, as the $F$-value is 135.49 with $p$ value $<0.0001$. This implies that there is only $0.01 \%$ chance that a Model $F$-value could occur due to noise. The lack-of-fit $F$-value of 1.75 confirms that the lack-of-fit is not significant. There is a $27.96 \%$ chance that a lack-of-fit $F$-value could occur because of noise. The nonsignificant lack-of-fit suggests that the model is precise enough for model prediction. The low coefficient of variation of 3.17 revealed high precision of the model and the experiment results are reliable. Meanwhile, the significance of the model is supported by its $R^{2}$ value of 0.9922 and adjusted $R^{2}$ value of 0.9848 . The $R^{2}$ value should be close to 1 , which implies that the experimental data fitted well with the model [25]. Adequate precision measures the signal to noise ratio, where a ratio greater than 4 is desirable. In this model, the value of 36.091 indicates an adequate signal, which can be used to navigate the design space. The coefficient of regression model and its significance for photocatalytic degradation of PAA is shown in Table 4.

In the photodecomposition of PAA, the operational parameters of the quadratic polynomial model terms of
$B, C, D, A^{2}, B^{2}, C^{2}$, and $D^{2}$ are highly significant as their $p$ value is less than 0.0001 . Other model terms, namely, $A C$, $A D, B C, B D$, and $C D$, are insignificant as their $p$ value is greater than 0.1000 . It should be noted that the initial concentration of PAA has high negative effect compared to the positive effect of solution $\mathrm{pH}$ and reaction time. This suggested that the concentration of PAA plays a significant role in the photocatalytic decomposition of PAA [26]. Based on the experimental results presented in Table 4, a secondorder polynomial equation was derived as shown in

$$
\begin{aligned}
R= & 82.74-2.07 A-10.38 B+4.30 C+6.69 D \\
& +1.73 A B+0.53 A C-0.18 A D+0.069 B C \\
& -0.15 B D-0.14 C D-10.42 A^{2}-3.56 B^{2} \\
& -6.43 C^{2}-2.08 D^{2},
\end{aligned}
$$

where $R$ is the percentage degradation of PAA and $A, B$, $C$, and $D$ are terms for the coded values of amount of $\mathrm{ZnO}$ loaded, initial concentration of PAA, solution $\mathrm{pH}$, and reaction time, respectively. The correlation between the experimental data against the values predicted by the response for the photodecomposition of PAA is shown in Figure 2. It can be seen that the values obtained via experimental approach were in good agreement with the predictive results $\left(R^{2}=0.9922\right)$, indicating that the model is adequate to explain the experimental ranges. Subsequently, residuals analysis (difference between the actual values and predictive values) was carried out to examine the adequacy of the model, as inadequate fit would give inaccurate or misleading results $[27,28]$. The plot of normal probability versus studentized residuals is illustrated in Figure 3. From Figure 3, all the residuals fall near to a straight line, indicating nonnormality of the experimental data [29]. In the plot of studentized residuals against predicted responses (Figure 4), all the points are randomly scattered within \pm 3.00 , implying that the model is adequate to explain the relationship between the studied operational parameters and the degradation efficiency of PAA [30].

3.2. Response Surface Analysis. Figure 5 shows the interaction effects of amount of $\mathrm{ZnO}$ loaded, initial concentration of $\mathrm{PAA}, \mathrm{pH}$ of the solution, and irradiation duration on the degradation efficiency of PAA. From the contour plot, it can be seen that the removal of PAA increased with increasing $\mathrm{ZnO}$ loaded up to $0.4 \mathrm{~g} / \mathrm{L}$ and then gradually decreased at higher loadings. When the amount of $\mathrm{ZnO}$ increases above its optimum mass, the penetration of UV light into the reaction 
TABLE 2: Central composite design with predictive values and their experimental results.

\begin{tabular}{|c|c|c|c|c|c|c|c|}
\hline \multirow[b]{2}{*}{ Standard } & \multirow[b]{2}{*}{ Point type } & \multicolumn{4}{|c|}{ Experimental parameters } & \multicolumn{2}{|c|}{ PAA degradation } \\
\hline & & $\begin{array}{c}\mathrm{ZnO} \text { loading } \\
(\mathrm{g} / \mathrm{L})\end{array}$ & $\begin{array}{c}\text { Initial concentration } \\
\text { of PAA }(\mathrm{mg} / \mathrm{L})\end{array}$ & Solution $\mathrm{pH}$ & $\begin{array}{l}\text { Reaction } \\
\text { time (min) }\end{array}$ & $\begin{array}{c}\text { Experimental } \\
(\%)\end{array}$ & $\begin{array}{c}\text { Predictive } \\
(\%)\end{array}$ \\
\hline 1 & Factorial & 0.30 & 15.00 & 6.00 & 20.00 & 63.13 & 63.58 \\
\hline 2 & Factorial & 0.50 & 15.00 & 6.00 & 20.00 & 54.68 & 55.27 \\
\hline 3 & Factorial & 0.30 & 25.00 & 6.00 & 20.00 & 40.72 & 39.52 \\
\hline 4 & Factorial & 0.50 & 25.00 & 6.00 & 20.00 & 35.59 & 38.14 \\
\hline 5 & Factorial & 0.30 & 15.00 & 8.00 & 20.00 & 71.73 & 71.27 \\
\hline 6 & Factorial & 0.50 & 15.00 & 8.00 & 20.00 & 63.36 & 65.60 \\
\hline 7 & Factorial & 0.30 & 25.00 & 8.00 & 20.00 & 45.64 & 47.49 \\
\hline 8 & Factorial & 0.50 & 25.00 & 8.00 & 20.00 & 47.66 & 48.21 \\
\hline 9 & Factorial & 0.30 & 15.00 & 6.00 & 40.00 & 78.24 & 77.90 \\
\hline 10 & Factorial & 0.50 & 15.00 & 6.00 & 40.00 & 68.37 & 68.88 \\
\hline 11 & Factorial & 0.30 & 25.00 & 6.00 & 40.00 & 52.58 & 53.24 \\
\hline 12 & Factorial & 0.50 & 25.00 & 6.00 & 40.00 & 50.47 & 51.14 \\
\hline 13 & Factorial & 0.30 & 15.00 & 8.00 & 40.00 & 85.22 & 85.03 \\
\hline 14 & Factorial & 0.50 & 15.00 & 8.00 & 40.00 & 76.71 & 78.12 \\
\hline 15 & Factorial & 0.30 & 25.00 & 8.00 & 40.00 & 61.03 & 60.64 \\
\hline 16 & Factorial & 0.50 & 25.00 & 8.00 & 40.00 & 58.74 & 60.65 \\
\hline 17 & Axial & 0.20 & 20.00 & 7.00 & 30.00 & 44.12 & 45.22 \\
\hline 18 & Axial & 0.60 & 20.00 & 7.00 & 30.00 & 40.58 & 36.92 \\
\hline 19 & Axial & 0.40 & 10.00 & 7.00 & 30.00 & 89.82 & 89.27 \\
\hline 20 & Axial & 0.40 & 30.00 & 7.00 & 30.00 & 49.76 & 47.75 \\
\hline 21 & Axial & 0.40 & 20.00 & 5.00 & 30.00 & 49.09 & 48.43 \\
\hline 22 & Axial & 0.40 & 20.00 & 9.00 & 30.00 & 67.53 & 65.63 \\
\hline 23 & Axial & 0.40 & 20.00 & 7.00 & 10.00 & 62.77 & 61.04 \\
\hline 24 & Axial & 0.40 & 20.00 & 7.00 & 50.00 & 88.65 & 87.81 \\
\hline 25 & Center & 0.40 & 20.00 & 7.00 & 30.00 & 80.16 & 82.74 \\
\hline 26 & Center & 0.40 & 20.00 & 7.00 & 30.00 & 83.22 & 82.74 \\
\hline 27 & Center & 0.40 & 20.00 & 7.00 & 30.00 & 83.05 & 82.74 \\
\hline 28 & Center & 0.40 & 20.00 & 7.00 & 30.00 & 81.55 & 82.74 \\
\hline 29 & Center & 0.40 & 20.00 & 7.00 & 30.00 & 85.02 & 82.74 \\
\hline 30 & Center & 0.40 & 20.00 & 7.00 & 30.00 & 83.41 & 82.74 \\
\hline
\end{tabular}

TABLE 3: ANOVA for the response surface quadratic model.

\begin{tabular}{lccccc}
\hline Source & Sum of squares & DF & Mean square & $F$ value & $p$ value \\
\hline Model & 7981.60 & 14 & 570.11 & 135.49 & $<0.0001$ \\
Residual & 63.12 & 15 & 4.21 & & Significant \\
Lack-of-fit & 49.07 & 10 & 4.91 & & Not significant \\
Pure error & 14.05 & 5 & 2.81 & & \\
& $R^{2}=0.9922$ & & Adj. $R^{2}=0.9848$ & \\
& C.V. $=3.17$ & & Adeq. precision $=36.091$ & & \\
& &
\end{tabular}

medium was reduced due to screening effect [31]. The decrement in the photodegradation efficiency may also result from the particle agglomeration, which reduces the active sites on the $\mathrm{ZnO}$ catalysts that have been exposed to UV illumination [32]. It is obvious that the degradation percentage decreased as the initial concentration of PAA increased. This is based on the fact that, as the concentration of PAA increases, the demand of oxidizing species such as ${ }^{\circ} \mathrm{OH}$ and ${ }^{\circ} \mathrm{O}_{2}{ }^{-}$also increases in order to photodegrade more molecules of PAA that adsorbed on the catalyst surface. However, the number of hydroxyl radicals available on the catalyst surface is insufficient to photodegrade PAA at higher concentrations as 
TABLE 4: Coefficient of regression model and its significance.

\begin{tabular}{|c|c|c|c|c|c|c|c|}
\hline Factor & $\begin{array}{l}\text { Coefficient } \\
\text { estimate }\end{array}$ & $\begin{array}{l}\text { Degree of } \\
\text { freedom }\end{array}$ & Standard error & $F$ value & $\begin{array}{l}\text { 95\% confidence } \\
\text { interval low }\end{array}$ & $\begin{array}{l}\text { 95\% confidence } \\
\text { interval high }\end{array}$ & $p$ value \\
\hline Intercept & 82.74 & 1 & 0.84 & - & 80.95 & 84.52 & - \\
\hline$A$ & -2.07 & 1 & 0.42 & 24.55 & -2.97 & -1.18 & 0.0002 \\
\hline$B$ & -10.38 & 1 & 0.42 & 614.58 & -11.27 & -9.49 & $<0.0001$ \\
\hline C & 4.30 & 1 & 0.42 & 105.44 & 3.41 & 5.19 & $<0.0001$ \\
\hline$D$ & 6.69 & 1 & 0.42 & 255.43 & 5.80 & 7.58 & $<0.0001$ \\
\hline$A B$ & 1.73 & 1 & 0.51 & 11.39 & 0.64 & 2.82 & 0.0042 \\
\hline$A C$ & 0.53 & 1 & 0.51 & 1.05 & -0.57 & 1.62 & 0.3216 \\
\hline$A D$ & -0.18 & 1 & 0.51 & 0.12 & -1.27 & 0.91 & 0.7332 \\
\hline$B C$ & 0.069 & 1 & 0.51 & 0.018 & -1.02 & 1.16 & 0.8942 \\
\hline$B D$ & -0.15 & 1 & 0.51 & 0.088 & -1.24 & 0.94 & 0.7712 \\
\hline$C D$ & -0.14 & 1 & 0.51 & 0.074 & -1.23 & 0.95 & 0.7895 \\
\hline$A^{2}$ & -10.42 & 1 & 0.39 & 707.31 & -11.25 & -9.58 & $<0.0001$ \\
\hline$B^{2}$ & -3.56 & 1 & 0.39 & 82.46 & -4.39 & -2.72 & $<0.0001$ \\
\hline$C^{2}$ & -6.43 & 1 & 0.39 & 269.23 & -7.26 & -5.59 & $<0.0001$ \\
\hline$D^{2}$ & -2.08 & 1 & 0.39 & 28.11 & -2.91 & -1.24 & $<0.0001$ \\
\hline
\end{tabular}

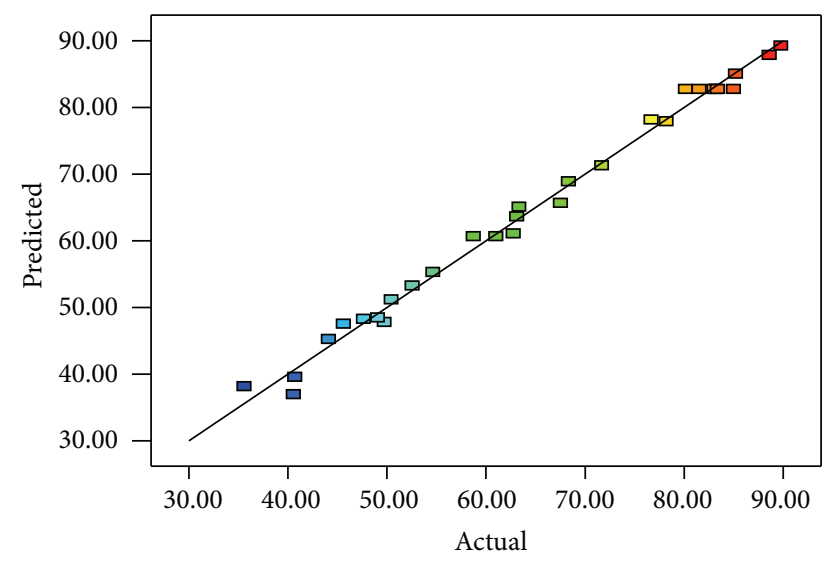

FIGURE 2: Predicted versus experimental values for photocatalytic degradation of PAA.

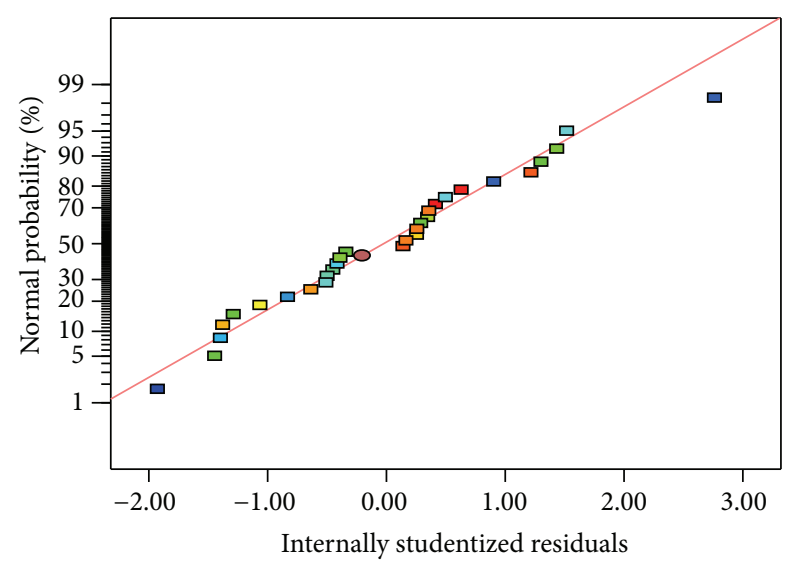

FIGURE 3: Normal probability plots of the residuals.

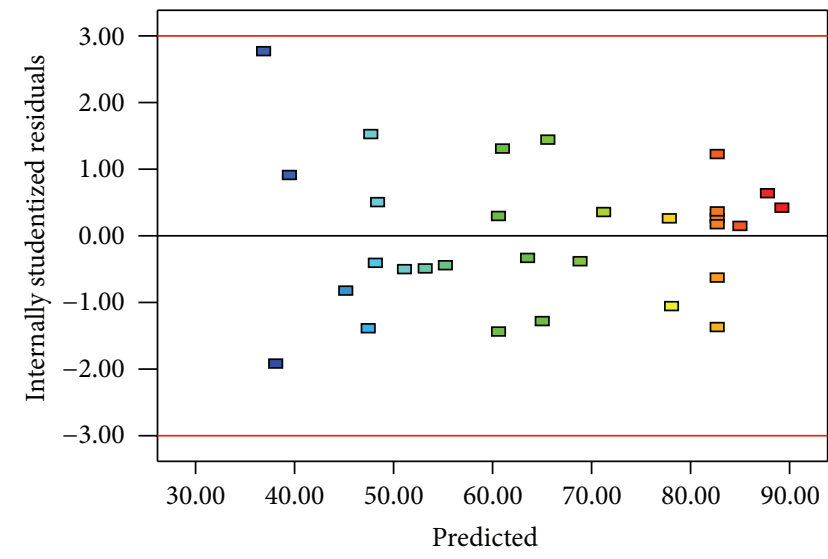

FIGURE 4: Plot of the residuals against the predicted response.

the amount of catalyst loaded, light intensity, and irradiation duration are fixed [33]. The rapid formation of degraded products during the photocatalytic reaction may compete for the hydroxyl radicals at higher concentration of PAA, which reduces the photodegradation efficiency as well [34]. It has been reported that the $\mathrm{pH}$ of the reaction medium has an impact on the electrostatic interaction between a catalyst surface, solvent molecules, substrate, and charged radicals formed during the photodegradation process [35]. The protonation and deprotonation of PAA molecules and $\mathrm{ZnO}$ catalyst surface could occur either in acidic or in alkaline conditions. Therefore, the $\mathrm{ZnO}$ surface is positively charged below 9.0 and the surface of PAA is negatively charged above $3.12\left(\mathrm{pK}_{\mathrm{a}}\right.$ of PAA $\left.=3.12\right)$. Hence, optimum photodegradation efficiency was observed at $\mathrm{pK}_{\mathrm{a}}<\mathrm{pH}<\mathrm{pH}_{\mathrm{zpc}}$. This is due to the electrostatic interaction enhancement between the positively charged $\mathrm{ZnO}$ surface and the negatively 


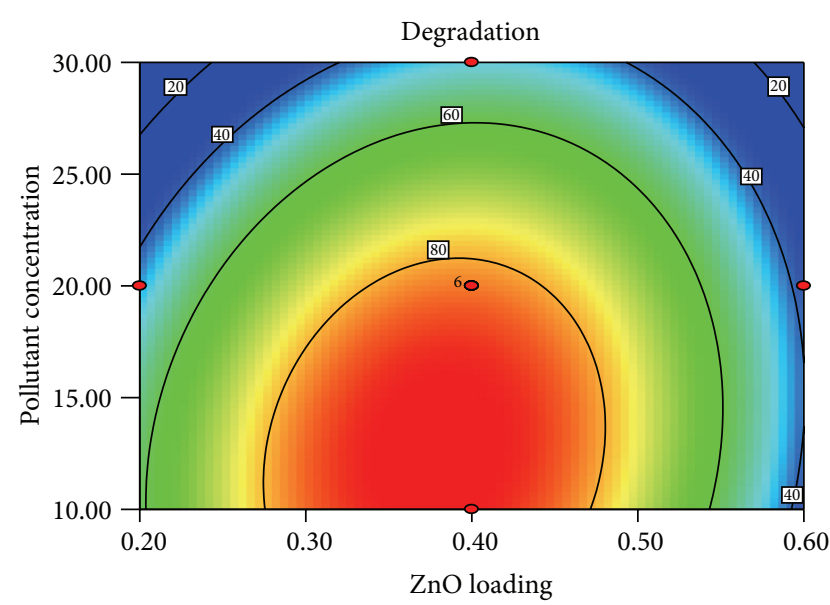

(a)

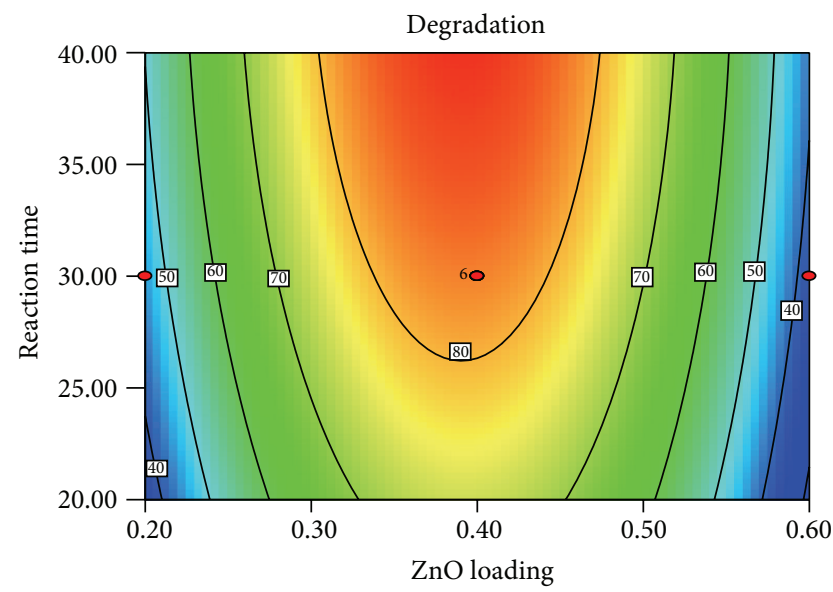

(c)

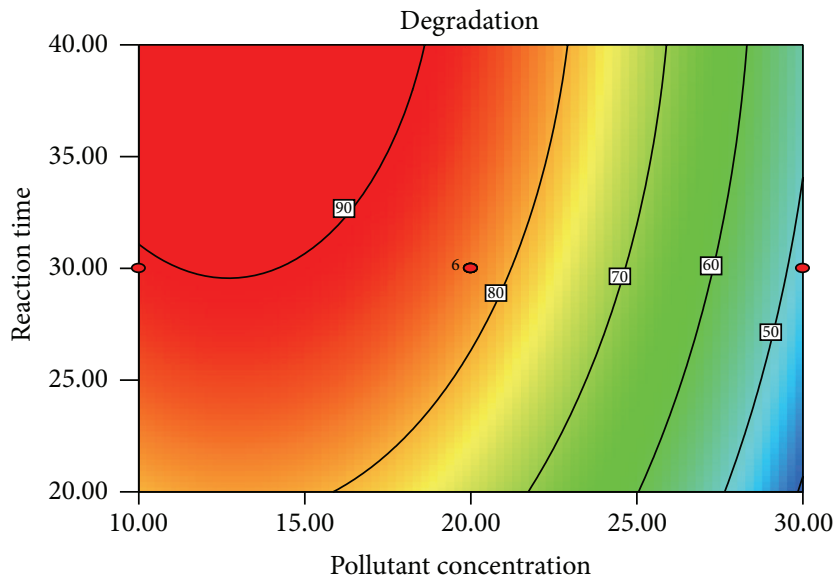

(e)

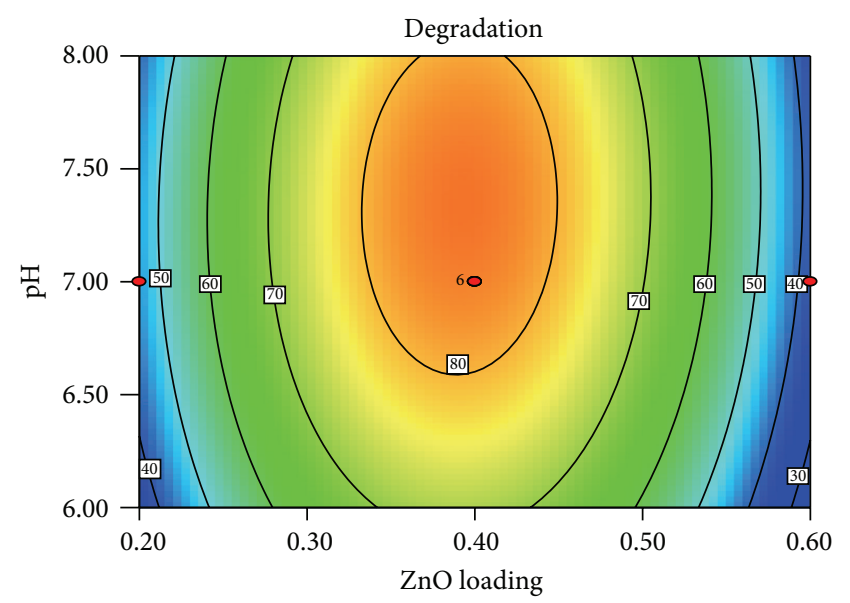

(b)

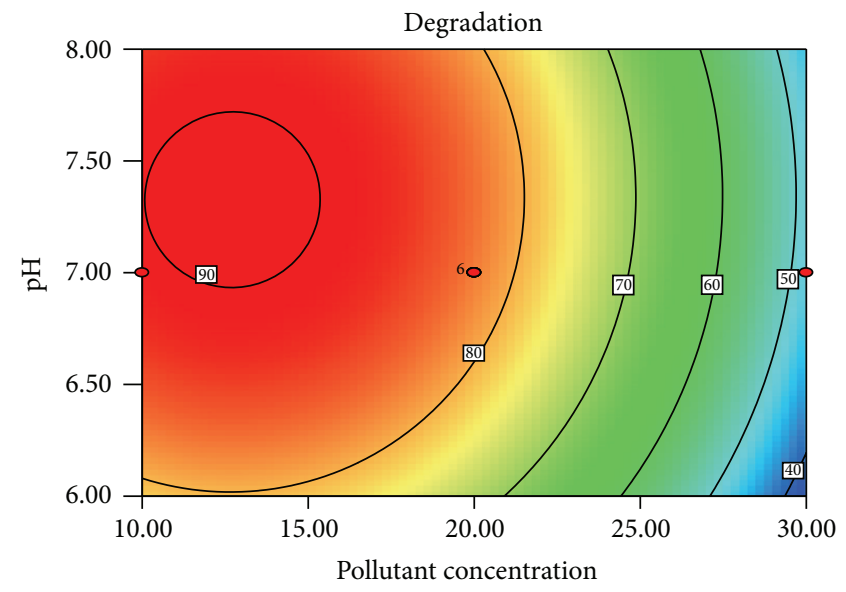

(d)

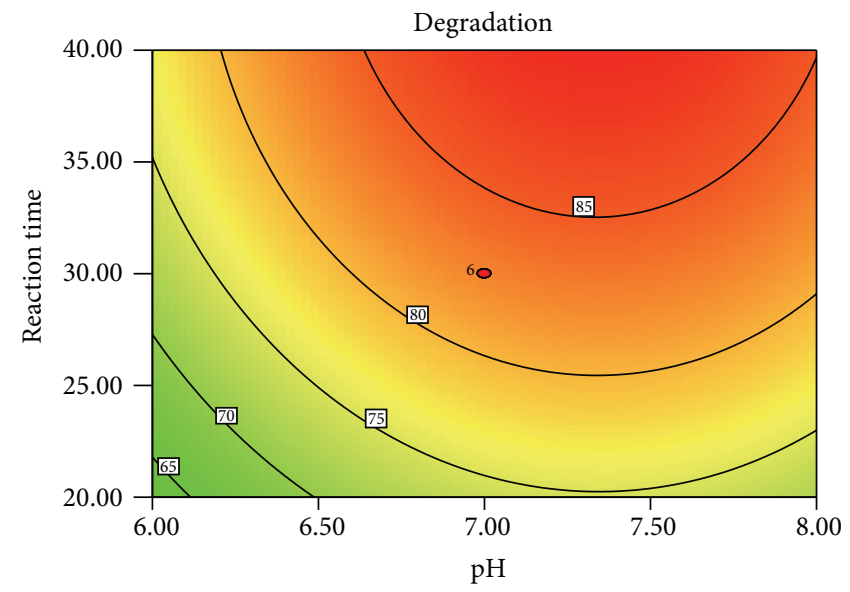

(f)

FIGURE 5: Interaction effects between studied parameters on the photodecomposition of PAA.

charged of PAA, which increased the photodegradation efficiency [36, 37]. The duration of exposure to UV irradiation also played a significant role in photodegrading PAA. The percentage of degradation increased with longer exposure duration, due to more photoinduced holes, and hydroxyl radicals will be generated, which facilitates the removal of PAA molecules [38].
3.3. Model Verification and Confirmation Test. The goal of a photocatalytic degradation reaction is to achieve greater degradation efficiency. Table 5 lists the optimization goal of each of the studied independent variables. Consequently, 5 sets of experiments were carried out to verify the derived response surface model according to the Design Expert software and the experimental and predictive results were 
TABLE 5: The optimization goals of photocatalytic degradation of PAA.

\begin{tabular}{|c|c|c|c|c|}
\hline Independent variables & Goal & Lower limit & Upper limit & Importance \\
\hline $\mathrm{ZnO}$ loading $(\mathrm{g} / \mathrm{L})$ & In the range & 0.30 & 0.50 & 3 \\
\hline Initial concentration of PAA $(\mathrm{mg} / \mathrm{L})$ & In the range & 15.00 & 25.00 & 3 \\
\hline Solution $\mathrm{pH}$ & In the range & 6.00 & 8.00 & 3 \\
\hline Reaction time (min) & In the range & 20.00 & 40.00 & 3 \\
\hline
\end{tabular}

TABLE 6: Comparison between experimental and predictive values for model verification.

\begin{tabular}{|c|c|c|c|c|c|c|}
\hline & oading $(g / L)$ & Initial concentration of PAA $(\mathrm{mg} / \mathrm{L})$ & Initial solution $\mathrm{pH}$ & Reaction time (min) & Experimental (\%) & Predictive $(\%)$ \\
\hline 1 & 0.40 & 17.00 & 7.93 & 39.00 & 89.54 & 90.13 \\
\hline 2 & 0.40 & 17.00 & 7.12 & 36.00 & 90.36 & 90.45 \\
\hline 3 & 0.40 & 19.00 & 7.21 & 39.00 & 90.15 & 89.92 \\
\hline 4 & 0.40 & 16.00 & 6.73 & 40.00 & 92.29 & 91.47 \\
\hline 5 & 0.40 & 15.00 & 7.01 & 32.00 & 90.78 & 90.49 \\
\hline
\end{tabular}

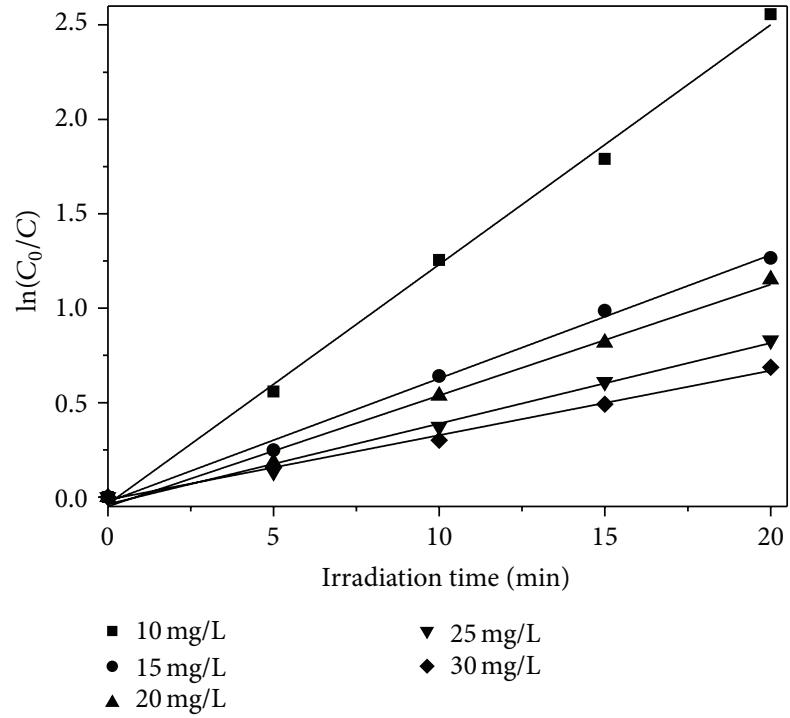

Figure 6: Kinetic plot of PAA by $\mathrm{ZnO}$ photocatalyst under UV-A irradiation.

shown in Table 6. As shown in Table 6, the experimental values were very close to the results predicted by the response surface software, which indicated that the developed model was reliable in optimizing the photocatalytic degradation of PAA.

3.4. Kinetics Analysis and Total Organic Carbon Removal of $P A A$. The Langmuir-Hinshelwood (L-H) kinetic model was used to describe the photocatalytic degradation rate of PAA by plotting the graph of $\ln \left(C / C_{0}\right)$ versus time, $t$, at different concentrations [39]:

$$
\ln \frac{C_{0}}{C}=k_{1} t
$$

where $C_{0}$ is the initial concentration of PAA $(\mathrm{mg} / \mathrm{L}), C$ is the PAA concentration after irradiation at time, $t$, and $k_{1}$ is the pseudo-first-order rate constant. The pseudo-firstorder rate constant was determined from the slope of the straight line (Figure 6). It is noteworthy that PAA with

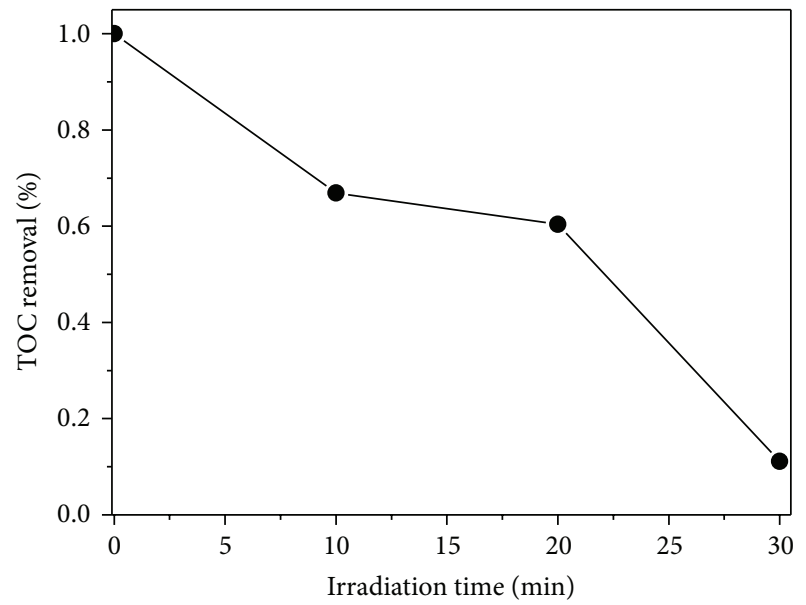

FIGURE 7: Effect of ZnO photocatalyst and UV irradiation on TOC removal in the photocatalytic degradation of PAA.

the lowest concentration $(10 \mathrm{mg} / \mathrm{L})$ exhibits the highest reaction rate $\left(0.127 \mathrm{~min}^{-1}\right)$, which is about 2 times greater than that of $20 \mathrm{mg} / \mathrm{L}$ PAA. The reaction rate is decreased at higher concentrations. Figure 7 shows that $90 \%$ TOC removal was achieved on the photocatalytic degradation of PAA with $\mathrm{ZnO}$ photocatalysts under UV-A irradiation over $30 \mathrm{~min}$, indicating photomineralization of PAA under UV/ZnO system.

3.5. Proposed Photocatalytic Degradation of PAA by UV/ZnO System. The photocatalytic reactions were initiated when the $\mathrm{ZnO}$ particle absorbs photons from UV or visible light. Upon the absorption of light, the electrons in the valence band (VB) of $\mathrm{ZnO}$ are promoted to the conduction band (CB), forming a positive hole in the valence band $\left(\mathrm{h}_{\mathrm{VB}}{ }^{+}\right)$. The photogenerated holes and electrons are able to induce oxidationreduction reaction of the PAA molecules. However, the rapid recombination of the electron-hole pairs which dissipates in the form of heat will slow down the photocatalytic degradation process. The presence of oxygen in the aqueous solution helps in forming the superoxide radicals $\left({ }^{\circ} \mathrm{O}_{2}{ }^{-}\right)$, which will 


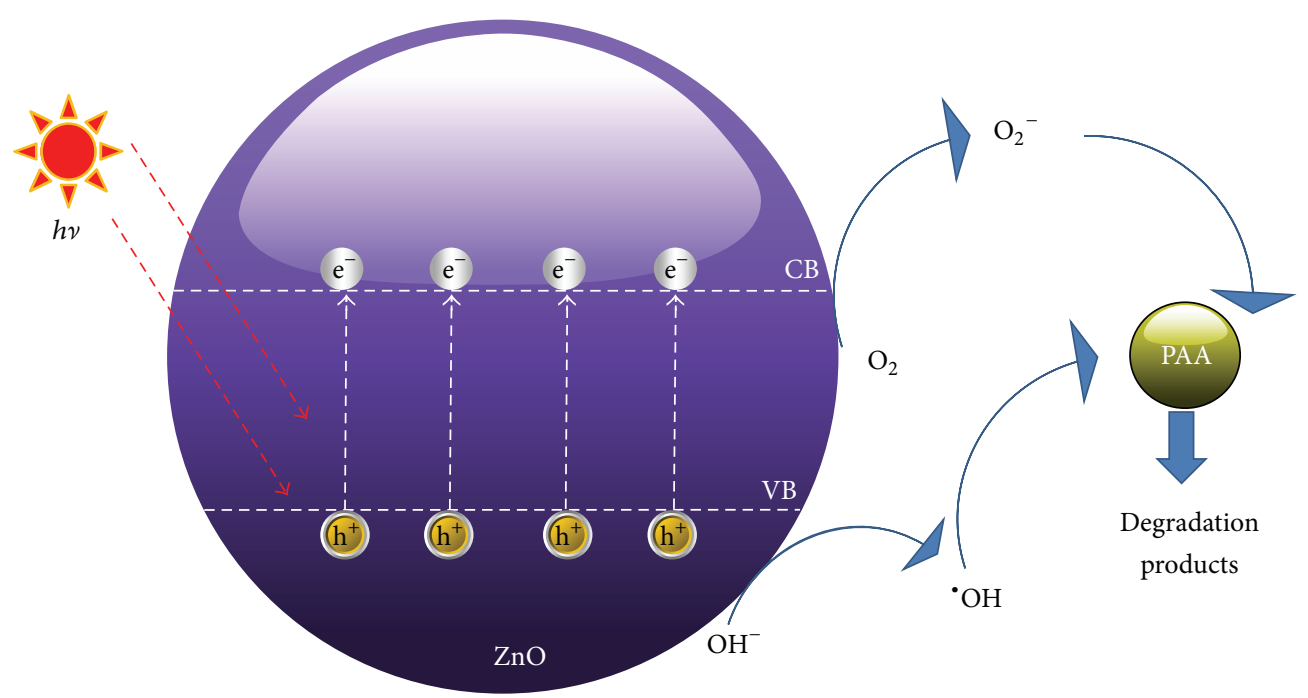

FIGURE 8: Schematic diagram of PCO of PAA by ZnO photocatalyst under UV irradiation.

then further protonate to hydroperoxyl radicals $\left(\mathrm{HOO}^{\bullet}\right)$. Both superoxide and hydroperoxyl radicals act as electron scavengers to trap the electrons from the conduction band of $\mathrm{ZnO}$, which in turn delay the recombination process. The superoxide and hydroxyl radicals will then react with the PAA molecules and lead to the partial or complete mineralization of PAA ((5)-(13)) [40-42]. The schematic diagram of PCO of PAA by $\mathrm{ZnO}$ photocatalyst under UV irradiation was shown in Figure 8. Consider

$$
\begin{aligned}
& \mathrm{ZnO}+\mathrm{hv} \longrightarrow \mathrm{ZnO}\left(\mathrm{e}^{-}{ }_{\mathrm{CB}}+\mathrm{h}^{+}{ }_{\mathrm{VB}}\right) \\
& \mathrm{ZnO}+\mathrm{H}_{2} \mathrm{O}_{\mathrm{ads}} \longrightarrow \mathrm{ZnO}+\mathrm{OH}^{-}+\mathrm{H}^{+} \\
& \mathrm{ZnO}\left(\mathrm{h}^{+}{ }_{\mathrm{VB}}\right)+\mathrm{OH}^{-} \longrightarrow \mathrm{ZnO}+{ }^{\circ} \mathrm{OH} \\
& \mathrm{ZnO}\left(\mathrm{e}_{\mathrm{CB}}{ }^{-}\right)+\mathrm{O}_{2} \longrightarrow \mathrm{ZnO}+\mathrm{O}_{2}^{\cdot-} \\
& \mathrm{O}_{2}{ }^{\cdot-}+\mathrm{H}^{+} \longrightarrow \mathrm{HO}_{2}{ }^{\bullet} \\
& \mathrm{HO}_{2}{ }^{\bullet}+\mathrm{O}_{2}^{\cdot-} \longrightarrow{ }^{\bullet} \mathrm{OH}+\mathrm{OH}^{-}+\mathrm{O}_{2} \\
& 2 \mathrm{HO}_{2}{ }^{\bullet} \longrightarrow \mathrm{H}_{2} \mathrm{O}_{2}+\mathrm{O}_{2} \\
& \mathrm{ZnO}\left(\mathrm{e}_{\mathrm{CB}}{ }^{-}\right)+\mathrm{H}_{2} \mathrm{O}_{2} \longrightarrow \mathrm{ZnO}+{ }^{\circ} \mathrm{OH}+\mathrm{OH}^{-} \\
& \mathrm{PAA}+\left(\mathrm{O}_{2}{ }^{\cdot-} \text { or }{ }^{\bullet} \mathrm{OH}\right) \longrightarrow \text { Degraded products } \\
& \longrightarrow \text { Mineralization }
\end{aligned}
$$

\section{Conclusion}

In summary, the PCO of PAA was carried out by $\mathrm{ZnO}$ photocatalyst under UV-A irradiation. Modelling of PAA photodegradation was performed via CCD coupled with RSM. The derived response surface model successfully optimized four process parameters, namely, amount of $\mathrm{ZnO}$ loaded, initial concentration of PAA, $\mathrm{pH}$ of the solution, and irradiation duration. More than $90 \%$ of PAA was degraded under optimized conditions of $0.04 \mathrm{~g} \mathrm{ZnO}$ loaded, $16 \mathrm{mg} / \mathrm{L}$ PAA, and solution $\mathrm{pH}$ of 6.73 in 40 minutes. In this study, the initial concentration of PAA was the most significant factor that affects the photodegradation of PAA.

\section{Conflict of Interests}

The authors declare that there is no conflict of interests regarding the publication of this paper.

\section{Acknowledgment}

The authors would like to thank University of Malaya for funding this research work under University of Malaya Research Grant (UMRG: RP022-2012A).

\section{References}

[1] H. Mestankova, B. Escher, K. Schirmer, U. von Gunten, and S. Canonica, "Evolution of algal toxicity during (photo)oxidative degradation of diuron," Aquatic Toxicology, vol. 101, no. 2, pp. 466-473, 2011.

[2] S. Sanches, M. T. Barreto Crespo, and V. J. Pereira, "Drinking water treatment of priority pesticides using low pressure UV photolysis and advanced oxidation processes," Water Research, vol. 44, no. 6, pp. 1809-1818, 2010.

[3] C. Tizaoui, K. Mezughi, and R. Bickley, "Heterogeneous photocatalytic removal of the herbicide clopyralid and its comparison with $\mathrm{UV} / \mathrm{H}_{2} \mathrm{O}_{2}$ and ozone oxidation techniques," Desalination, vol. 273, no. 1, pp. 197-204, 2011.

[4] S. P. Kamble, S. B. Sawant, and V. G. Pangarkar, "Photocatalytic mineralization of phenoxyacetic acid using concentrated solar radiation and titanium dioxide in slurry photoreactor," Chemical Engineering Research and Design, vol. 84, no. 5, pp. 355-362, 2006.

[5] H. M. Badawi, "DFT versus Møller-Plesset conformational profile and vibrational assignments of non-planar phenoxyacetic 
acid and 2,3,4,5,6- pentafluorophenoxyacetic acid," Journal of Molecular Structure, vol. 977, no. 1-3, pp. 67-71, 2010.

[6] H. M. Badawi and W. Förner, "Analysis of the infrared and Raman spectra of phenylacetic acid and mandelic (2-hydroxy2-phenylacetic) acid," Spectrochimica Acta-Part A: Molecular and Biomolecular Spectroscopy, vol. 78, no. 3, pp. 1162-1167, 2011.

[7] M. Shanthi and S. Kabilan, "Substituent and solvent effects on electronic spectra of some substituted phenoxyacetic acids," Spectrochimica Acta, Part A: Molecular and Biomolecular Spectroscopy, vol. 67, no. 2, pp. 479-482, 2007.

[8] K. Li, P. Zhang, L. Ge et al., "Concentration-dependent photodegradation kinetics and hydroxyl-radical oxidation of phenicol antibiotics," Chemosphere, vol. 111, pp. 278-282, 2014.

[9] M. Sánchez-Polo, M. M. A. Daiem, R. Ocampo-Pérez, J. RiveraUtrilla, and A. J. Mota, "Comparative study of the photodegradation of bisphenol A by $\mathrm{HO} \bullet, \mathrm{SO}_{4}{ }^{-}$and $\mathrm{CO}_{3} \bullet^{-} / \mathrm{HCO}_{3} \bullet$ radicals in aqueous phase," Science of the Total Environment, vol. 463-464, pp. 423-431, 2013.

[10] E. G. L. Oliveira, J. J. Rodrigues Jr., and H. P. de Oliveira, "Influence of surfactant on the fast photodegradation of rhodamine $\mathrm{B}$ induced by $\mathrm{TiO}_{2}$ dispersions in aqueous solution," Chemical Engineering Journal, vol. 172, no. 1, pp. 96-101, 2011.

[11] I. Kim and H. Tanaka, "Photodegradation characteristics of PPCPs in water with UV treatment," Environment International, vol. 35, no. 5, pp. 793-802, 2009.

[12] R. C. Pawar, H. Kim, and C. S. Lee, "Defect-controlled growth of $\mathrm{ZnO}$ nanostructures using its different zinc precursors and their application for effective photodegradation," Current Applied Physics, vol. 14, no. 4, pp. 621-629, 2014.

[13] M. B. Akin and M. Oner, "Photodegradation of methylene blue with sphere-like $\mathrm{ZnO}$ particles prepared via aqueous solution," Ceramics International, vol. 39, no. 8, pp. 9759-9762, 2013.

[14] P. Shukla, I. Fatimah, S. Wang, H. M. Ang, and M. O. Tadé, "Photocatalytic generation of sulphate and hydroxyl radicals using zinc oxide under low-power UV to oxidise phenolic contaminants in wastewater," Catalysis Today, vol. 157, no. 1-4, pp. 410-414, 2010.

[15] S. Anandan, N. Ohashi, and M. Miyauchi, "ZnO-based visiblelight photocatalyst: band-gap engineering and multi-electron reduction by co-catalyst," Applied Catalysis B: Environmental, vol. 100, no. 3-4, pp. 502-509, 2010.

[16] A. Rezaee, H. Masoumbeigi, R. D. C. Soltani, A. R. Khataee, and S. Hashemiyan, "Photocatalytic decolorization of methylene blue using immobilized $\mathrm{ZnO}$ nanoparticles prepared by solution combustion method," Desalination and Water Treatment, vol. 44, no. 1-3, pp. 174-179, 2012.

[17] M. A. Behnajady, N. Modirshahla, and R. Hamzavi, "Kinetic study on photocatalytic degradation of C.I. Acid Yellow 23 by ZnO photocatalyst," Journal of Hazardous Materials, vol. 133, no. 1-3, pp. 226-232, 2006.

[18] H. K. Singh, M. Saquib, M. M. Haque, M. Muneer, and D. W. Bahnemann, "Titanium dioxide mediated photocatalysed degradation of phenoxyacetic acid and 2,4,5-trichlorophenoxyacetic acid, in aqueous suspensions," Journal of Molecular Catalysis A: Chemical, vol. 264, no. 1-2, pp. 66-72, 2007.

[19] M. Trillas, J. Peral, and X. Domènech, "Photocatalyzed degradation of phenol, 2,4-dichlorophenol, phenoxyacetic acid and 2,4-dichlorophenoxyacetic acid over supported $\mathrm{TiO}_{2}$ in a flow system," Journal of Chemical Technology and Biotechnology, vol. 67, no. 3, pp. 237-242, 1996.

[20] R. Das, S. Sarkar, and C. Bhattacharjee, "Photocatalytic degradation of chlorhexidine-a chemical assessment and prediction of optimal condition by response surface methodology," Journal of Water Process Engineering, vol. 2, pp. 79-86, 2014.

[21] A. H. Abdullah, H. J. M. Moey, and N. A. Yusof, "Response surface methodology analysis of the photocatalytic removal of Methylene Blue using bismuth vanadate prepared via polyol route," Journal of Environmental Sciences, vol. 24, no. 9, pp. 1694-1701, 2012.

[22] S.-P. Sun and A. T. Lemley, " $p$-Nitrophenol degradation by a heterogeneous Fenton-like reaction on nano-magnetite: process optimization, kinetics, and degradation pathways," Journal of Molecular Catalysis A: Chemical, vol. 349, no. 1-2, pp. 71-79, 2011.

[23] R. H. Myers and D. C. Montgomery, Response Surface Methodology: Process and Product Optimization Using Designed Experiments, John Wiley \& Sons, New York, NY, USA, 2nd edition, 2002.

[24] V. A. Sakkas, M. A. Islam, C. Stalikas, and T. A. Albanis, "Photocatalytic degradation using design of experiments: a review and example of the Congo red degradation," Journal of Hazardous Materials, vol. 175, no. 1-3, pp. 33-44, 2010.

[25] S. Chatterjee, A. Kumar, S. Basu, and S. Dutta, "Application of response surface methodology for methylene blue dye removal from aqueous solution using low cost adsorbent," Chemical Engineering Journal, vol. 181-182, pp. 289-299, 2012.

[26] C. Sahoo and A. K. Gupta, "Optimization of photocatalytic degradation of methyl blue using silver ion doped titanium dioxide by combination of experimental design and response surface approach," Journal of Hazardous Materials, vol. 215-216, pp. 302-310, 2012.

[27] R. Meng and X. Yu, "Investigation of ultrasound assisted regeneration of Ni-bentonite with response surface methodology (RSM)," Applied Clay Science, vol. 54, no. 1, pp. 112-117, 2011.

[28] Y. J. Wen and Y. H. Wu, "Optimizing adsorption of Co(II) and $\mathrm{Ni}(\mathrm{II})$ by $13 \times$ molecular sieves using response surface methodology," Water, Air, and Soil Pollution, vol. 223, no. 9, pp. 6095-6107, 2012.

[29] F. Shahrezaei, Y. Mansouri, A. A. L. Zinatizadeh, and A. Akhbari, "Process modeling and kinetic evaluation of petroleum refinery wastewater treatment in a photocatalytic reactor using $\mathrm{TiO}_{2}$ nanoparticles," Powder Technology, vol. 221, pp. 203-212, 2012.

[30] R. D. C. Soltani, A. Rezaee, A. R. Khataee, and M. Safari, "Photocatalytic process by immobilized carbon black/ZnO nanocomposite for dye removal from aqueous medium: optimization by response surface methodology," Journal of Industrial and Engineering Chemistry, vol. 20, no. 4, pp. 1861-1868, 2014.

[31] B. Gao, P. S. Yap, T. M. Lim, and T.-T. Lim, "Adsorptionphotocatalytic degradation of Acid Red 88 by supported $\mathrm{TiO}_{2}$ : effect of activated carbon support and aqueous anions," Chemical Engineering Journal, vol. 171, no. 3, pp. 1098-1107, 2011.

[32] K. Hayat, M. A. Gondal, M. M. Khaled, S. Ahmed, and A. M. Shemsi, "Nano ZnO synthesis by modified sol gel method and its application in heterogeneous photocatalytic removal of phenol from water," Applied Catalysis A: General, vol. 393, no. 1-2, pp. 122-129, 2011.

[33] C. Lu, Y. Wu, F. Mai et al., "Degradation efficiencies and mechanisms of the $\mathrm{ZnO}$-mediated photocatalytic degradation of Basic Blue 11 under visible light irradiation," Journal of Molecular Catalysis A: Chemical, vol. 310, no. 1-2, pp. 159-165, 2009.

[34] U. I. Gaya and A. H. Abdullah, "Heterogeneous photocatalytic degradation of organic contaminants over titanium dioxide: 
a review of fundamentals, progress and problems," Journal of Photochemistry and Photobiology C: Photochemistry Reviews, vol. 9, no. 1, pp. 1-12, 2008.

[35] M. Kosmulski, "pH-dependent surface charging and points of zero charge: III. Update," Journal of Colloid and Interface Science, vol. 298, no. 2, pp. 730-741, 2006.

[36] H. Zhu, R. Jiang, Y. Fu et al., "Effective photocatalytic decolorization of methyl orange utilizing $\mathrm{TiO}_{2} / \mathrm{ZnO} /$ chitosan nanocomposite films under simulated solar irradiation," Desalination, vol. 286, pp. 41-48, 2012.

[37] C. Wang, J. Zhao, X. Wang et al., "Preparation, characterization and photocatalytic activity of nano-sized $\mathrm{ZnO} / \mathrm{SnO}_{2}$ coupled photocatalysts," Applied Catalysis B: Environmental, vol. 39, no. 3, pp. 269-279, 2002.

[38] M. Fathinia, A. R. Khataee, M. Zarei, and S. Aber, "Comparative photocatalytic degradation of two dyes on immobilized $\mathrm{TiO}_{2}$ nanoparticles: effect of dye molecular structure and response surface approach," Journal of Molecular Catalysis A: Chemical, vol. 333, no. 1-2, pp. 73-84, 2010.

[39] K. V. Kumar, K. Porkodi, and F. Rocha, "Langmuir-Hinshelwood kinetics-a theoretical study," Catalysis Communications, vol. 9, no. 1, pp. 82-84, 2008.

[40] P. V. L. Reddy, K.-H. Kim, and H. Song, "Emerging green chemical technologies for the conversion of $\mathrm{CH}_{4}$ to value added products," Renewable and Sustainable Energy Reviews, vol. 24, pp. 578-585, 2013.

[41] D. Zhang, X. Liu, and X. Wang, "Growth and photocatalytic activity of $\mathrm{ZnO}$ nanosheets stabilized by Ag nanoparticles," Journal of Alloys and Compounds, vol. 509, no. 15, pp. 4972-4977, 2011.

[42] A. Fujishima, X. Zhang, and D. A. Tryk, " $\mathrm{TiO}_{2}$ photocatalysis and related surface phenomena," Surface Science Reports, vol. 63, no. 12, pp. 515-582, 2008. 

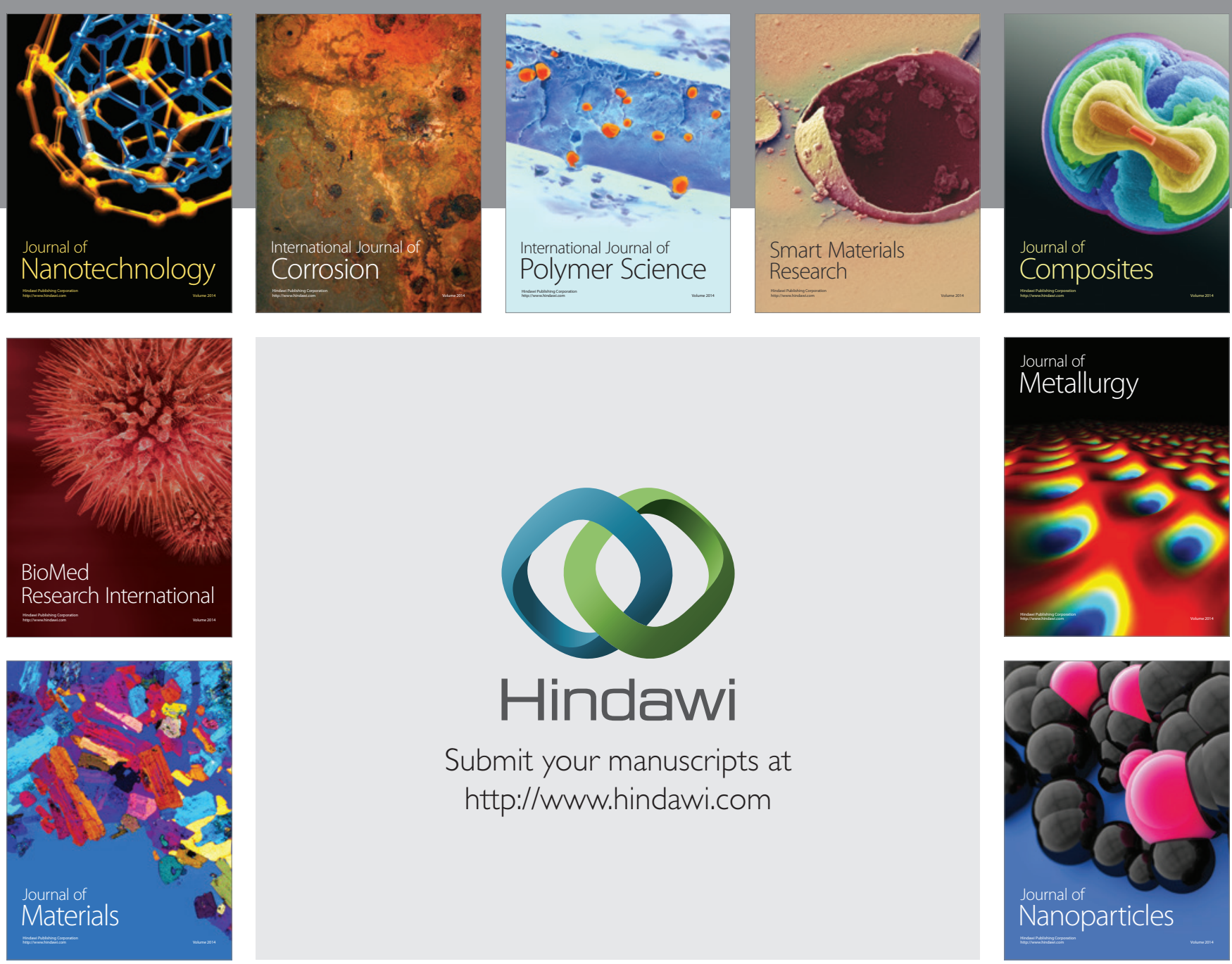

Submit your manuscripts at http://www.hindawi.com
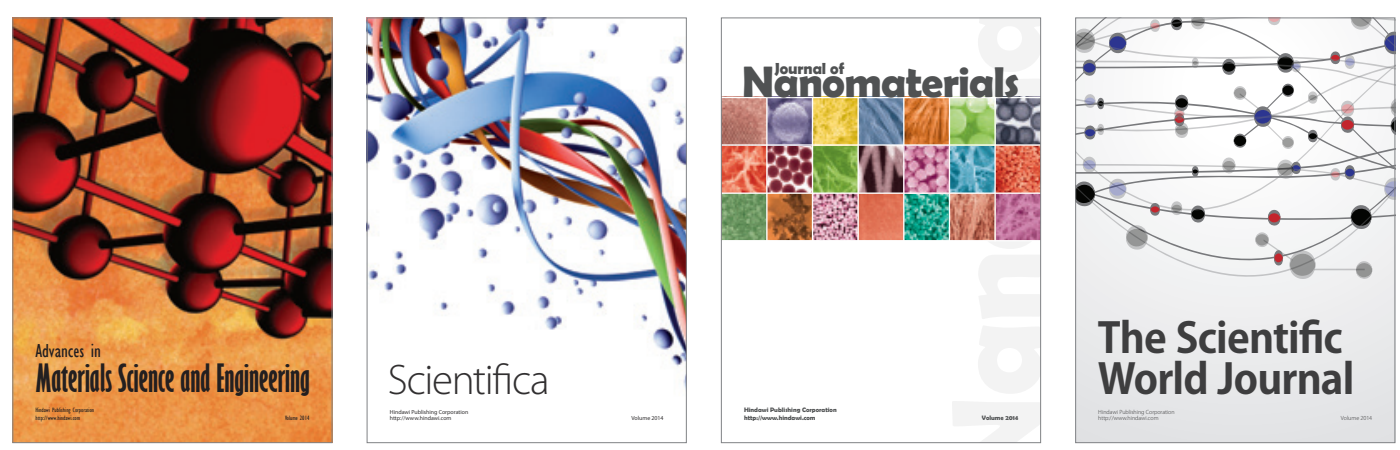

\section{The Scientific World Journal}
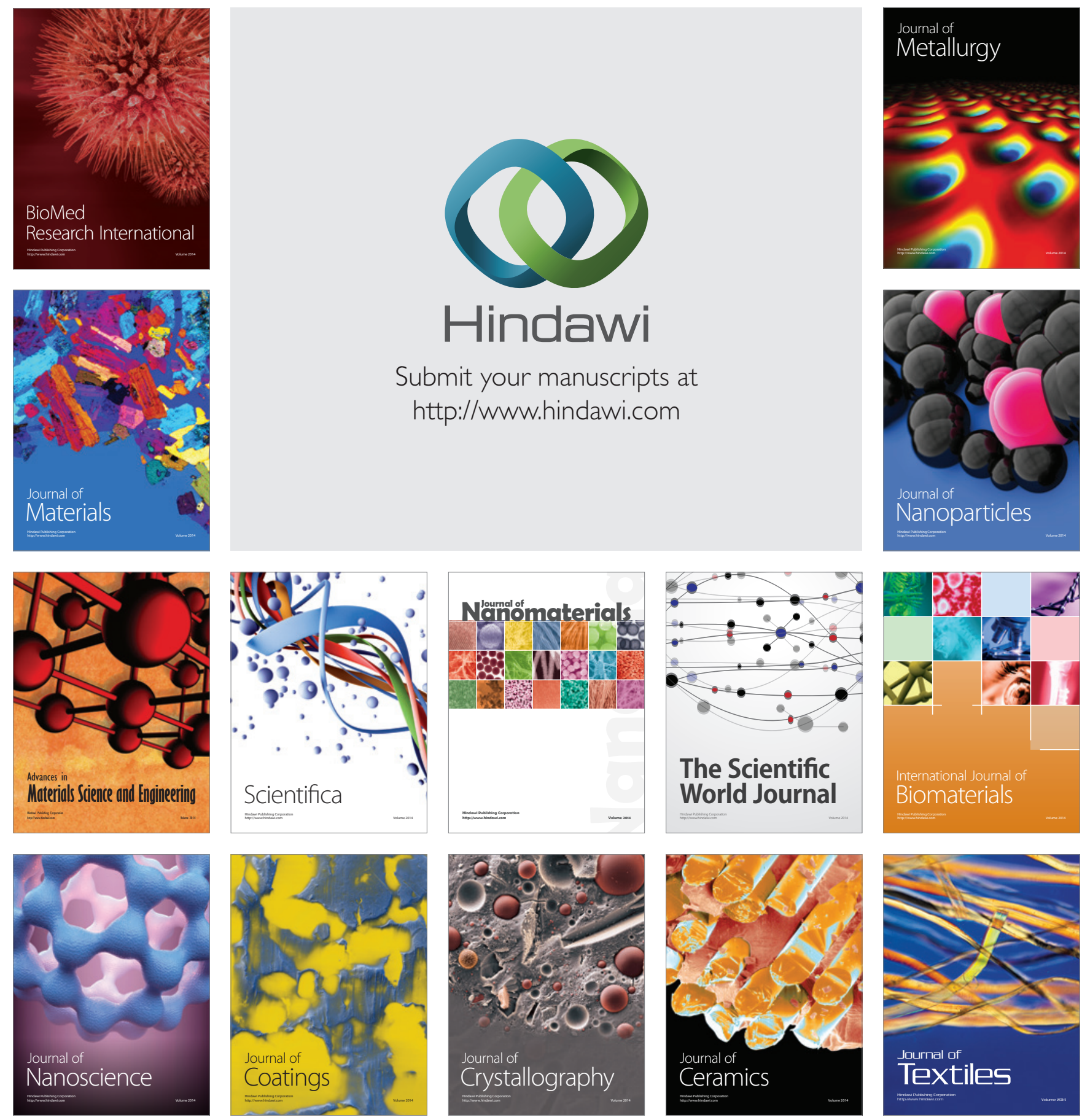